RU Языковое сознание персонажа в художественном тексте постмодерна: когнитивно-прагматический аспект

\author{
Кудрявцева М.И.
}

\begin{abstract}
Аннотация. Цель статьи состоит в выявлении и описании когнитивно-прагматических характеристик репрезентации языкового сознания персонажа в постмодернистском художественном тексте. Научная новизна проведенного исследования заключается в обосновании определяющей роли интертекстуальности в репрезентации языкового сознания персонажа и в трансформации художественной реальности. В результате установлено, что в романе С. Соколова «Школа для дураков», одном из наиболее репрезентативных текстов в плане объективации языкового сознания, автор в художественном тексте постмодерна является таким же фрагментом художественной реальности, как и персонаж, а языковое сознание героя выступает лингвокогнитивным способом репрезентации индивидуально-авторской картины мира.
\end{abstract}

\title{
Character's Linguistic Consciousness in Postmodernity Literary Text: Cognitive-Pragmatic Aspect
}

\author{
Kudryavtseva M. I.
}

\begin{abstract}
The purpose of the article is to identify and describe the cognitive-pragmatic characteristics of representation of a character's linguistic consciousness in a postmodernist literary text. Scientific novelty of the study lies in providing rationale for the defining role of intertextuality in representation of a character's linguistic consciousness and in literary reality transformation. As a result, it is found that in S. Sokolov's novel "A School for Fools", one of the most representative texts in terms of linguistic consciousness objectification, the author in the postmodernity literary text is the same fragment of literary reality as a character, while a character's linguistic consciousness functions as a linguo-cognitive way of representing the individual author's worldview.
\end{abstract}

\section{Введение}

Лингвистика последних десятилетий обращается к изучению проблемы «человека говорящего», что обусловливает понимание языка не только как системы знаков, которая фиксируется сознанием, но и как речемыслительной деятельности: «...сознание в своей непосредственности есть открывающаяся субъекту картина мира, в которую включен он сам, его действия и состояния» [9, с. 166]. Языковое сознание рассматривается наукой о языке с позиций неразрывной связи языка и деятельности человека, а значит, оно представляет собой когнитивный и психолингвистический феномен, реализуемый в процессе коммуникации и совместной деятельности людей.

Языковое сознание трактуется как совокупность «образов сознания, формируемых и овнешняемых при помощи языковых средств - ассоциативных полей» [17]. Актуальность исследования состоит в необходимости выявления и адекватного описания объективации языкового сознания в процессе речемыслительной деятельности, в том числе в художественном тексте как ее результате, т.к. оно «может быть исследовано только как продукт психической деятельности, имеющей эксплицитное выражение в формах артефактов, отчужденных от субъекта сознания» [Там же]. Особое значение приобретает также изучение специфики манифестирования языкового сознания в авторской и персонажной зонах повествования, прежде всего, в постмодернистских текстах с позиций когнитивной лингвистики и лингвопрагматики.

Задачи исследования:

1) охарактеризовать особенности репрезентации языкового сознания в художественном тексте постмодерна с позиций нового гуманизма;

Научная статья (original research article) । https://doi.org/10.30853/phil210353

(c) 2021 Авторы. ООО Издательство «Грамота» (๔ 2021 The Authors. GRAMOTA Publishers). Открытый доступ предоставляется на условиях лицензии СС BY 4.0 (open access article under the CC BY 4.0 license): https://creativecommons.org/licenses/by/4.0/ 
2) выявить и описать маркеры интертекстуальности в языковом сознании персонажа;

3) рассмотреть интертекстуальность в художественном тексте постмодерна как один из лингвокогнитивных способов репрезентации индивидуально-авторской картины мира через языковое сознание персонажа.

Методы исследования представляют собой единый комплекс, применяемый к материалу - тексту романа С. Соколова «Школа для дураков» (1973, первая публикация - 1976) [16], основными среди методов являются методы наблюдения и сопоставления, индуктивно-дедуктивный метод и интерпретативный метод, прагматический и семантический анализ художественного текста.

Теоретическую основу исследования составляют работы, посвященные разработке концепций языкового сознания $[3 ; 15 ; 17 ; 18 ; 20 ; 22]$. Важным представляется также обращение к работам по проблематике художественного текста $[4 ; 6]$, в том числе в аспекте изучения репрезентации эмоций как важной составляющей внутреннего мира автора и персонажа [19; 21]. Определяющее место в рамках теоретико-методологической базы исследования занимают работы, в которых параметрированы особенности художественного текста постмодерна с позиций лингвистики [7] и литературоведения [8; 10], а также обоснован статус интертекстуальности в парадигме постмодернизма и современной культуре в целом [5].

Практическая значимость исследования состоит в выработке алгоритма анализа художественного текста постмодерна с позиций аспектов нового гуманизма, невозможности описания мира как целого и, как следствие, отсутствия таких репрезентантов индивидуально-авторской картины мира, которые принадлежали бы исключительно авторской зоне повествования: автор сам становится фрагментом художественной реальности. Персонаж в этом случае рассматривается не только как результат творческой деятельности автора, но и как итог эстетической когниции постмодернистского текста читателем.

\section{Языковое сознание в художественном тексте постмодерна с позиций нового гуманизма}

Основные принципы когнитивистики детерминированы пониманием сознания человека как феномена, который определенным образом постулирует окружающий мир. Именно когнитивистика формирует в настоящий момент методологию гуманитарной научной парадигмы, что во много определяет и ориентирование личности в действительности [12]. Когнитивная сфера рассматривается как динамическая структура восприятия и понимания информации, а «человеческий фактор» трактуется как система, активно адаптирующаяся к среде и способная мыслить, что определяет ведущую роль субъектности, т.к. человек предстает как герой перемен в мире.

Безусловно, основные постулаты когнитивистики обусловливают и те позиции, с которых изучается текст: автор рассматривается как творческий субъект, запечатлевающий картину мира в ее индивидуально-авторской интерпретации, а сам художественный текст мыслится как объективация языкового сознания его продуцента. Представляется, что постмодернистский художественный текст обладает обширным эвристическим потенциалом в плане изучения специфики манифестирования в нем языкового сознания автора и персонажа.

Постмодернизм, являясь результатом новой культурно-исторической эпохи, постмодерна, представляет собой литературное направление, в настоящее время активно осмысляемое в координатах филологии. Объектом изображения постмодернизма становится мир в его кризисном состоянии, исчерпавший идеи прогресса, веры в Разум, пессимистический, но ощущающий потребность в преодолении такого состояния, в том числе посредством создания новой культуры. Мы согласны с А. В. Кузнецовой в том, что «эстетическая практика направлена в основном на трансформацию уже существующих кодов, что, в свою очередь, влечет за собой “размывание” границ между элитарной и массовой культурами. Следствием этого глобального процесса становятся новые типы текстов, для которых характерен плюрализм индивидуально-авторских интенций и картин мира, систем ценностей и художественных миров. Поэтому можно с уверенностью утверждать, что постмодерн в культуре определяет множественность, проявляющуюся в различных сферах жизнедеятельности человечества и имеющую семиотический характер» [8, с. 156].

Для постмодерна вообще свойственна универсальность нового гуманизма: не только человек, но и все живое, природа в целом вовлечены в его орбиту. Такое осмысление мира закономерно отражено в тексте романа С. Соколова, что обусловливает наличие сложных синтаксических целых, демонстрирующих соположение персонажа и окружающей его действительности, равное положение всех объектов, «населяющих» этот мир, например: «...северная ветка, ветка акации или, скажем, сирени, цветет белыми цветами, пахнет креозотом, пылью тамбура, куревом... ветка спит, но поезда, симметрично расположенные на ней, воспаленно бегут в темноте цепочками, окликая по имени каждый цветок, обрекая бессоннице желчных станционных старух, безногих и ослепленных войной вагонных гармонистов, сизых путевых обходчиков в оранжевых безрукавках, умных профессоров и безумных поэтов, дачных изгоев и неудачников - удильщиков ранней и поздней рыбы, путающихся в пружинистых сплетениях прозрачной лесы, а также пожилых бакенщиков островитян, чьи лица, качающиеся над медно гудящими черными водами фарватера, попеременно бледны или алы, и, наконец, служащих лодочных пристаней, кому мерещится звон отвязанной лодочной цепи, плеск весел, шорох паруса» [16, с. 14]. В приведенном макроконтексте значимым становится синтез авторского и персонажного сознания, причем художественный текст постмодерна организован таким образом, чтобы в продуцируемом автором художественном тексте читатель распознавал речевые характеристики персонажа, прилагая к этому определенные интеллектуальные усилия. Так, в сложном синтаксическом целом (ССЦ) примечательно само метафорическое переосмысление лексемы ветка, известное как профессионализм в сфере железнодорожного транспорта, однако 
в художественном тексте эта лексема лишь постепенно приобретает новое метафорическое значение, превращаясь из ветки дерева в железнодорожную ветку (поезда... бегут... окликая по имени каждый цветок).

Такие синтаксические явления в художественном тексте свидетельствуют, разумеется, о «децентрации субъекта», свойственной эпохе постмодерна: утверждается множественность интерпретаций, отвергнуты детерминизм, сама идея завершенности познания. Художественный текст постмодерна также фиксирует и уничтожение границ различных областей знания, манифестируя данное явление рядами однородных членов: «...если сегодня ветер шевелит мои волосы, освежает лицо, задувает за ворот рубашки, продувает карманы и рвет пуговицы пиджака, а завтра ломает ненужные ветхие постройки, вырывает с корнем дубы, возмущает и вздувает водоемы и разносит семена моего сада по всему свету» [Там же, с. 26]. Лексемы и лексические сочетания, включенные в синтаксические структуры в приведенном контексте, репрезентируют разные пространственно-временные пласты и объекты, а их сочетание создает мозаичную картину, объективируя языковое сознание персонажа и маркируя значимые компоненты индивидуально-авторской картины мира.

\section{Интертекстуальность в языковом сознании персонажа в художественном тексте постмодерна}

Постмодернистский художественный текст характеризуется полиадресатностью: с одной стороны, такой текст может быть адекватно интерпретирован читателем, который знаком с культурными кодами разных эпох, с прецедентными феноменами, источники которых могут быть весьма разнообразны и специфичны в прагматическом отношении. В этом случае художественному тексту свойственна стилизация, пародийность, ирония. Последняя квалифицируется как интеллектуальная провокация, поскольку если понимание не наступает, то и коммуникативная задача иронии не реализована [7]. С другой стороны, постмодернистский текст адресован и массовому читателю, однако этот адресат воспринимает и декодирует только поверхностные текстовые структуры. Тем не менее и этот адресат способен осуществлять рецептивно-интерпретативную деятельность по отношению к художественному тексту, зачастую верно распознавая и такие цитаты, которые имеют в настоящее время клишированный характер. Так, например, в следующем контексте: «Знайте, други, на свете счастья нет, ничего подобного, ничего похожего, но зато - Господи! - есть же, в конце концов, покой и воля» [16, с. 25] адекватно распознается и декодируется имплицированная цитата из стихотворения А. С. Пушкина «Пора, мой друг, пора! покоя сердце просит...» (1834): «На свете счастья нет, / Но есть покой и воля» [13], которая трансформирована в тексте романа С. Соколова в речь одного из персонажей (в контексте выделено курсивом). Кроме того, в приведенном контексте представлена также реминисценция к лирической поэзии А. С. Пушкина в виде обращения други (ср., например, его стихотворение «Элегия» (1830): «Но не хочу, о други, умирать...» [14]). Приведенный фрагмент манифестирует прецедентное высказывание, входящее в состав национальной картины мира, т.к. указанные стихотворения А. С. Пушкина включены в программу изучения литературы в средней общеобразовательной школе и практически каждый носитель русской лингвокультуры с данными прецедентными высказывания знаком и может активизировать их в своей культурной памяти.

Поскольку задачи постмодернизма не включают отражения действительности, в нем в еще большей степени, нежели в каком-либо другом литературном направлении, осознана необходимость в создании «иной» реальности, которая характеризуется не только разнообразными причинно-следственными связями, несвойственными реальному миру, но и функционированием в нем симулякров, копий при отсутствии оригиналов. Автор постмодернистского художественного текста не имеет цели самовыражения: напротив, он дистанцирован от мира, который самостоятельно организовывается в его тексте, и наблюдает со стороны за этим процессом. Основным механизмом, позволяющим воссоздать такой самоорганизовывающийся мир и выразить его через языковое сознание персонажа, маркеры которого вербализованы в тексте, не прибегая к средствам авторской оценочности, становится интертекстуальность. Интертекстуальность для постмодерна, по Ю. Кристевой, не является простой совокупностью цитат [5]: напротив, посредством цитирования нивелируются какиелибо фиксированные, закрепленные за каждой цитатой, за каждым прецедентным феноменом смысл, ассоциация. В романе С. Соколова интертекстуальность основывается на адекватно декодируемых читателем прецедентных именах, высказываниях, ситуациях и текстах, сферой-источником которых являются лирическая поэзия и песни советского периода, а также художественные тексты, принадлежащие к русской классике XIX в.

Общеизвестна тенденция постмодерна к обессмысливанию цитат и реминисценций, однако мы не можем утверждать этого в отношении текста романа «Школа для дураков». Скорее, здесь обратный процесс: художественный текст усложняется семантически, не только манифестируя лингвокреативный потенциал автора, но и провоцируя рецептивно-интерпретативную деятельность читателя. Так, в следующем контексте: «Не кажется ли вам, мой юный товарищ, что пора бы уже, как говорится, грянуть буре, грозе? Норвегов посмотрел в небо, рукой глаза свои заслонив от солнца. И ведь грянет, милый вы мой, да еще как грянет - полетят клочки по закоулочкам!» [16, с. 21] - репрезентированы интертекстуальные отсылки сразу к нескольким текстам-источникам: обращение мой юный товарищ позволяет читателю восстановить аллюзивные связи с текстовым корпусом советской литературы, в которой лексические сочетания такого характера чрезвычайно распространены; ряд лексических сочетаний грянуть буре, грозе, ведь грянет, да еще как грянет имеет своим источником «Песню о Буревестнике» (1901) М. Горького [2]; полетят клочки по закоулочкам - отсылка к русской народной сказке «Лиса, заяц и петух» [11, с. 21-23].

В художественном тексте С. Соколова интертекстуальность - одна из значимых характеристик языкового сознания персонажа, мальчика, который учится в школе для детей с задержкой психического развития. Характеризуя 
его внутреннюю речь, которая многообразно репрезентирована в виде внутренних монологов, автор часто не дифференцирует авторское и персонажное сознание, однако читатель должен интерпретировать контексты корректно, сообразуясь с эстетическими задачами романа: С. Соколов настаивает на том, что внешние проявления поведенческой нормы отнюдь не всегда свидетельствуют о психической нормальности и наоборот. Именно поэтому отсылки к разным эпохам и культурам в этом художественном тексте представляются необходимыми характеристиками языкового сознания персонажа, например: «Безмозглое панургово стадо, обделанное мухами и клопами!» [16, с. 26]. Приведенный контекст отсылает читателя к роману Ф. Рабле «Гаргантюа и Пантагрюэль».

\section{Языковое сознание персонажа}

\section{как лингвокогнитивный способ репрезентации индивидуально-авторской картины мира}

Интертекстуальность в постмодернистском художественном тексте не является облигаторным признаком языкового сознания автора или персонажа: напротив, это онтологическая характеристика самой эстетической когниции, свойственной адресанту такого текста, которая проецируется и на рецептивно-интерпретативную деятельность адресата. Так, С. Соколов использует в тексте своего романа интертекстуальные отсылки к Новому завету: «...ты должен наконец стать честным, как Павел, он же и Савл» [Там же, с. 40], что, несомненно, маркирует семантическое пространство художественного текста таким образом, чтобы адресат имел возможность декодировать специфику языкового сознания персонажа. Исходя из библейских аллюзий и реминисценций, которые оказываются значимыми во внутренней речи героя, понятно, что его мир гораздо более эмоционально и духовно насыщен, чем могут представить внешние наблюдатели его жизни. В приведенном примере имя Павел, которое носит учитель мальчика, «ученика такого-то», соотносится в языковом сознании героя с первоапостолом Павлом, который до крещения носил имя Савл (ивр. Шауль, по всей видимости, назван в честь древнееврейского царя Саула, первого царя народа Израиля, основателя единого Израильского царства). Также и в следующем фрагменте: «Великой правды захочется вам. И тогда приду я. Я приду и приведу с собой убиенных и униженных вами и скажу: вот вам ваша правда и возмездие вам. И от ужаса и печали в лед обратится ваш рабский гной, текущий у вас в жилах вместо крови» [Там же, с. 26-27] - весьма заметно влияние библейских текстов, что закономерно выводит на первый план в художественном тексте романа С. Соколова и языковом сознании персонажа вечную тему истины и лжи, которая является ключевой в данном романе и тем не менее подвергается сомнению, как и вообще художественная реальность, неспособная, по определению, транслировать истинностные смыслы.

Также интересен следующий фрагмент: «Он говорил, что ощущает себя настолько худым, что боится, как бы его не унес какой-нибудь случайный ветер. Врачи, - смеялся Норвегов, - запретили мне подходить к ветряным мельницам ближе чем на километр, но запретный плод сладок: меня ужасно к ним тянет, они совсем рядом с моим домом, на полынных холмах, и когда-нибудь я не выдержу» [Там же, с. 25]. Отметим, что в приведенном макроконтексте представлена многоуровневая реализация различных прецедентных феноменов. Само упоминание ветряных мельниц, разумеется, соотносит героя с вечным образом мировой литературы Дон Кихотом, героем романа М. де Сервантеса Сааведра «Хитроумный идальго Дон Кихот Ламанчский» (1605). Запрет подходить ближе чем на определенное расстояние - отсылка к обычной правовой практике в западноевропейских странах и США, весьма узнаваемым и обычно верно декодируемым прецедентным высказыванием является поговорка запретный плод сладок, имеющая своим источником ветхозаветный сюжет о грехопадении Адама и Евы. В приведенном макроконтексте имплицитно репрезентирован и прецедентный феномен, сложно декодируемый адресатом: высказывание рядом с моим домом, на полынных холмах отсылает читателя к произведению живописи - пейзажу кисти М. Волошина «Мои долины лукоморья, мои полынные холмы» (1927).

Интертекстуальность в художественном тексте постмодерна направлена на создание нового языка культуры, что обусловливает динамический характер самого текста. Художественный текст принципиально «вторичен», не имеет автора в привычном представлении, не является законченным [1]. Р. Барт указывает, что современная литература нуждается в тексте, а не в произведении, и в этом случае литература перестает испытывать идеологическое давление, может избежать воздействия социальных стереотипов и сохранить тем самым свою эстетическую сущность. В таком тексте прекращает свое существование авторское сознание, а все внимание адресанта фокусируется на продуцировании «многоуровневого диалога» культурных кодов, который, в свою очередь, формирует онтологическую доминанту постмодернистского текста: «Каждый постмодернистский текст, оборачиваясь интертекстом, претендует не только на подобие, но на полное, по крайней мере структурное, тождество мироустройству... В постмодернистской интертекстуальности проступают свойства мифологического типа миромоделирования, поскольку именно в мифологии целостность бытия запечатлевается непосредственно в объекте изображения. Структура мира абсолютно адекватна структуре мифа» [10, с. 17]. Так автор приобретает характеристики функции текста, становясь фрагментом художественной реальности, запечатленной в тексте.

\section{Заключение}

Художественный текст постмодерна характеризуется отсутствием собственно авторской точки зрения, оценочности в традиционном понимании, что вовсе не исключает активного функционирования субъектов 
художественной реальности - автора, повествователя, рассказчика, персонажа. Наиболее активным и сложным компонентом в структуре художественного текста постмодерна является персонаж, который наделяется языковым сознанием ввиду реализации в постмодернистской парадигме нового гуманизма, включающего не только персонажа, но и окружающий его мир как равноправные в эстетической когниции объекты. При этом элиминация из числа принципов поэтики постмодернизма психологизма не затрагивает стабильного внимания к внутреннему миру персонажа.

Интертекстуальность как определяющее качество языкового сознания персонажа призвана отразить идею невозможности описания мира как целого, что обеспечивает усложненность эстетической когниции: персонаж познает непознаваемую реальность, являющуюся результатом художественного вымысла, сам, в свою очередь, также являясь вымыслом, фрагментом этой реальности. Автор также мыслится как фрагмент художественной реальности. Языковое сознание персонажа трансформирует художественную реальность посредством обращения к прецедентным феноменам, через интертекстуальность.

Интертекстуальность в языковом сознании персонажа является одним из лингвокогнитивных способов репрезентации индивидуально-авторской картины мира. Постмодерн декларирует принцип бесконечности мира, отвергая рационализм как единственный способ понимания и обоснования действительности, что, однако, не уничтожает вовсе в художественном тексте возможность выражения миропонимания автора через языковое сознание персонажа.

Перспективы дальнейшего исследования состоят в выявлении критериев, позволяющих адекватно дифференцировать в художественном тексте постмодерна языковое сознание собственно автора, автора как фрагмента художественной реальности и персонажа. Особый аспект исследования составляет определение приоритетных для конкретного автора или ряда авторов прецедентных феноменов, позволяющих создавать многомерность повествовательных пластов и многоуровневость авторской и персонажной зон повествования.

\section{Источники | References}

1. Барт Р. Избранные работы. Семиотика. Поэтика. М.: Прогресс, 1989. 616 с.

2. Горький М. Песня о Буревестнике [Электронный ресурс]. URL: https://ilibrary.ru/text/1493/p.1/index.html (дата обращения: 03.07.2021).

3. Камалова А. А. Ум в русском языковом сознании // Вестник Балтийского федерального университета им. И. Канта. Серия «Филология, педагогика, психология». 2016. № 1. С. 19-25.

4. Косиков Г. К. Структура и/или текст (стратегии современной семиотики) // От структурализма к постструктурализму. Французская семиотика / пер. с фр., сост. и вступ. ст. Г. К. Косикова. М.: Прогресс, 2000. С. 3-48.

5. Кристева Ю. Избранные труды. Разрушение поэтики. Изменение функций литературы. М.: Российская политическая энциклопедия (РОССПЭН), 2004. 656 с.

6. Кузнецова А. В. Рецептивно-интерпретативное пространство художественного текста: проблемная парадигма // Филологические науки. Вопросы теории и практики. 2019. Т. 12. Вып. 12. С. 118-121.

7. Кузнецова А. В. Топос иронии в рецептивно-интерпретативном пространстве художественного текста постмодерна // Актуальные проблемы филологии и педагогической лингвистики. 2020. № 2. С. 125-132.

8. Кузнецова А. В. Эстетическая когниция постмодерна: жанр как игра // Актуальные проблемы филологии и педагогической лингвистики. 2020. № 3. С. 153-161.

9. Леонтьев А. Н. Деятельность. Сознание. Личность. М.: Наука. 1975. 167 с.

10. Липовецкий М. Русский постмодернизм: очерки исторической поэтики. Екатеринбург: УрГПУ, 1997. 317 с.

11. Народные русские сказки. Из сборника А. Н. Афанасьева / вступ. ст. В. Аникина. М.: Правда, 1982. 576 с.

12. Ортега-и-Гассет Х. Запах культуры: сб. ст. / пер. с исп. М.: Алгоритм; Эксмо, 2006. 381 с.

13. Пушкин А. С. Пора, мой друг, пора, покоя сердце просит... [Электронный ресурс]. URL: https://rvb.ru/pushkin/ 01text/01versus/0423_36/1834/0592.htm (дата обращения: 03.07.2021).

14. Пушкин А. С. Элегия («Безумных лет угасшее веселье...») [Электронный ресурс]. URL: https://rvb.ru/pushkin/ 01text/01versus/0423_36/1830/0536.htm (дата обращения: 03.07.2021).

15. Сиркия Н. П. Когнитивная метафора как отражение содержания языкового сознания // Филологические науки. Вопросы теории и практики. 2018. № 5 (83). Ч. 1. С. 159-164.

16. Соколов С. Школа для дураков. СПб.: Азбука; Азбука-Аттикус, 2020. 256 с.

17. Тарасов Е. Ф. Актуальные проблемы анализа языкового сознания [Электронный ресурс]. URL: https://ilingran.ru/library/psylingva/sborniki/Book2000/html_204/1-3.html (дата обращения: 03.07.2021).

18. Ушакова Т. Н. Языковое сознание и принципы его исследования // Языковое сознание и образ мира: сб. ст. / отв. ред. Н. В. Уфимцева. М.: ИЯ РАН, 2000. С. 13-19.

19. Филимонова О. Е. Язык эмоций в английском тексте (когнитивный и коммуникативный аспекты). СПб.: РГГУ, 2001. 259 с.

20. Цыбенова Ч. С. Языковое сознание в контексте исследования языковой ситуации // Вестник Новосибирского государственного университета. Серия «Лингвистика и межкультурная коммуникация». 2018. № 3. С. $56-65$.

21. Шаховский В. И. Эмоционально-смысловая доминанта в естественной и художественной коммуникации // Язык и эмоции: личностные смыслы и доминанты в речевой деятельности. Волгоград, 2004. С. 147-168.

22. Яковлев А. А. «Языковое сознание» и «языковая картина мира»: совместимость понятий // Вестник Новосибирского государственного университета. Серия «Лингвистика и межкультурная коммуникация». 2018. № 2. С. 57-69. 


\section{Информация об авторах | Author information}

RU Кудрявцева Мария Игоревна ${ }^{1}$, к. филол. н.

${ }^{1}$ Южный федеральный университет, г. Ростов-на-Дону

EN Kudryavtseva Mariya Igorevna ${ }^{1}, \mathrm{PhD}$

${ }^{1}$ Sothern Federal University, Rostov-on-Don

${ }^{1}$ mia@sfedu.ru

Информация о статье | About this article

Дата поступления рукописи (received): 16.06.2021; опубликовано (published): 30.07.2021.

Ключевые слова (keywords): художественный текст; постмодерн; языковое сознание; интертекстуальность; прагматика; literary text; postmodernity; linguistic consciousness; intertextuality; pragmatics. 